American Journal of Animal and Veterinary Sciences 5 (2): 132-138, 2010

ISSN 1557-4555

(C) 2010 Science Publications

\title{
Effect of Sugar Cane Extract, Commercial Probiotic and their Mixture on Growth Performance and Intestinal Histology in Broiler Chickens
}

\author{
${ }^{1}$ Oraya Khambualai, ${ }^{1}$ Koh-en Yamauchi, ${ }^{1}$ Jassada Ruttanavut, \\ ${ }^{1}$ Tossaporn Incharoen and ${ }^{2}$ Jun Kashimura \\ ${ }^{1}$ Laboratory of Animal Science, Department of Applied Biological Science, \\ Faculty of Agriculture, Kagawa University, Miki-cho, Kagawa-ken, 761-0795, Japan \\ ${ }^{2}$ Department of Research Laboratory, Mitsui Sugar Co., Ltd, Kanagawa, Japan
}

\begin{abstract}
Problem statement: As the intestinal function is intimately affected by fed diets, many kinds of natural substances and probiotics have been supplemented to broilers to raise poultry productivity due to activating intestinal function. Besides, the intestinal histology is clearly altered by intestinal functions. The aim of this study was to investigate whether Sugar Cane Extract (SCE) and commercial probiotic (SPB), either alone or in combination, could improve growth performance and how intestinal histological alterations would be observed in these birds. Approach: A total of 64, 7-dold male broiler chicks were randomly assigned to 4 treatment groups, consisting of 4 replicates of 4 birds each. Commercial mash starter and finisher diets were supplemented with $0.05 \%$ SCE, $0.4 \%$ SPB, or a mixture of $0.05 \%$ SCE and $0.4 \%$ SPB (SCE + SPB). Results: Body weight gain was better in all the experimental groups than the control. The greatest improvement was observed in the SCE + SPB group. Most values of villus height, villus area, cell area and cell mitosis in all intestinal segments were higher $(\mathrm{p}<0.05)$ in the experimental groups than in the control group. Most epithelial cells on the villus apical surface of the experimental groups were composed of protuberant cells. In addition, cell clusters composed of these cells were observed in the duodenum of the SCE + SPB group and in the jejunum of the SCE group. In the ileum, the SCE + SPB group had the most protuberant cells. Conclusion: The present results of enhanced light microscopic parameters and protuberant epithelial cells in SCE and SPB groups suggest that the intestinal villi and epithelial cells might be hypertrophied by SCE and SPB. The fact that a synergistic effect was observed with regard to growth performance and intestinal histology in the SCE + SPB group suggests that SCE is a good supplement to probiotics.
\end{abstract}

Key words: Sugar cane extract, probiotics, chicken, villi, small intestine

\section{INTRODUCTION}

Various studies have demonstrated that probiotics can increase the growth performance and pathogen control of chickens. Living microorganisms have been used as probiotics, which induce health benefits beyond inherent basic nutrition (Guarner and Schaafsma, 1998). Most probiotic microorganisms belong to the lactic acid bacteria, such as Lactobacillus spp., Bifidobacterium spp. and Enterococcus spp. (Klein et al., 1998). The dietary supplementation of Lactobacillus has been manipulated to achieve E. acervulina reduction by altering intestinal intraepithelial lymphocyte subpopulations in chickens (Dalloul et al., 2003) and reduced Salmonella in day-ofhatch broilers (Higgins et al., 2007). A variety of yeast species are also used as probiotics. Supplementation with yeast such as Saccharomyces spp. can improve the immune functions of chickens by stimulating the secretion of secretory $\operatorname{IgA}$ in the intestine (Gao et al., 2008). Spring et al. (2000) indicated that feeding dietary yeast to chickens could reduce the colonies of pathogenic microorganisms such as Salmonella in the ceca. Furthermore, yeast products could improve body weight gain and feed efficiency of broiler chickens (Zhang et al., 2005). Another health-enhancing compound as a feed additive is Sugar Cane Extract (SCE). The main component of SCE is nitrogen-free extract $(46.5 \%)$ and dietary SCE stimulates the immune system against $E$. tenella infection (El-Abasy et al., 2003) and has growth promoting effects (El-Abasy et al., 2002) by activating intestinal functions (Yamauchi et al., 2006) in chickens.

Corresponding Author: Koh-en Yamauchi, Laboratory of Animal Science, Department of Applied Biological Science, Faculty of Agriculture, Kagawa University, Miki-cho, Kagawa-ken, 761-0795, Japan Tel/Fax: +81-87-891-3053 
Based on the closely related effects of probiotic microorganisms and SCE on the intestinal immune system, it is possible that they could together enhance the resistance of the host to enteric pathogens. Therefore, the purpose of this study was to observe the effect of SCE and SPB, either alone or in combination on growth performance and histological intestinal alterations in broiler chickens.

\section{MATERIALS AND METHODS}

Sugar cane extract preparation: Sugar cane juice was produced from sugar cane (Saccharum officinarum L.) via the raw sugar manufacturing process. Sugar cane extract $\left(169 \mathrm{~g}\right.$ of $\mathrm{CP} \mathrm{kg}^{-1}, 5 \mathrm{~g}$ of fat $\mathrm{kg}^{-1}, 465 \mathrm{~g}$ of nitrogen free extract $\mathrm{kg}^{-1}$ and $361 \mathrm{~g}$ of ash $\mathrm{kg}^{-1}$ ) was prepared by Mitsui Sugar Co., Ltd. (Tokyo, Japan) as follows. Most sugar components, such as glucose, fructose and sucrose from sugar cane juice, were separated by ion exchange column chromatography using synthetic adsorbent to produce SCE. Then, this SCE was adsorbed to an oilcake of rice-bran (DM basis; 1:4) and dried for dietary supplement.

Commercial probiotic: The commercial probiotic product (Super-BioLicks®; SPB) provided by Nippon Formular Feed MFG. Co., Ltd. (Tochigi, Japan). It mainly consisted of Leuconostoc spp. $\left(10^{7} \mathrm{CFU} \mathrm{g}^{-1}\right)$,

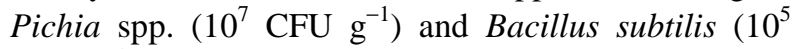
CFU g $\left.{ }^{-1}\right)$.

Animal and feeding experiments: The experiment was carried out in accordance with the guidelines for regulation of the Laboratory of Animal Science, Kagawa University, Japan. A total of sixty-four, 7-dayold male Marshall Chunky broiler chickens were used in a growth performance trial with 4 treatments and 4 replicates of 4 chicks each. The birds were housed in wire pens under daily lighting regimen of $24 \mathrm{~h}$ of light and environmental room temperature. A conventional mash diet (Nichiwa Sangyo Co., Ltd., Kagawa, Japan) (Table 1) was provided as basal diet. Diets were supplemented with $0.05 \%$ SCE, $0.4 \%$ SPB and combination of SCE and SPB (SCE + SPB) for a total of four treatments. Birds were fed with experimental starter and finisher diets from 7-21 and 22-49-day-old, respectively. Feed and water were allowed ad libitum access throughout the feeding periods. Feed consumption and body weight were recorded weekly.
Table 1: Feed formulation and nutrient composition of commercial broiler starter and finisher mash diet (\%)

\begin{tabular}{lcc}
\hline & Starter & Finisher \\
Item & $1-21$ days & $22-49$ days \\
\hline Ingredients & 51.00 & 58.00 \\
Ground maize & 2.00 & 9.00 \\
Milo & 37.00 & 22.00 \\
Soybean meal & 4.00 & 4.00 \\
Fish meal & 4.00 & 4.60 \\
Animal fat & - & 0.60 \\
Rapeseed meal & 1.00 & 0.85 \\
Calcium carbonate & 0.70 & 0.65 \\
Calcium phosphate tribasic & 0.15 & 0.15 \\
Sodium chloride & 0.15 & 0.15 \\
Vitamin/ mineral premix ${ }^{1}$ & & \\
Calculated chemical component & 23.50 & 18.00 \\
Crude protein & 3100.00 & 3200.00 \\
Metabolizable energy $\left(\mathrm{kcal}^{-1} \mathrm{~kg}^{-1}\right)$ & 4.00 & 4.00 \\
Crude fiber & 4.50 & 6.00 \\
Crude fat & 0.80 & 0.70 \\
Calcium & 0.60 & 0.55 \\
Phosphorus & &
\end{tabular}

${ }^{1}$ Concentrate mixture including (per kg of diet): vitamin A $10800 \mathrm{IU}$, Vitamin D3 $2000 \mathrm{IU}$, vitamin E $25 \mathrm{mg}$, vitamin K3 $2 \mathrm{mg}$, vitamin B1 $5.40 \mathrm{mg}$, vitamin B2 $7.20 \mathrm{mg}$, vitamin B6 $10.20 \mathrm{mg}$, vitamin B12 $8 \mu \mathrm{g}$, biotin $0.30 \mathrm{mg}$, pantothenic acid $17 \mathrm{mg}$, folic acid $1.10 \mathrm{mg}$, nicotinic acid $70.20 \mathrm{mg}$, choline $1,500 \mathrm{mg}$, zinc $80 \mathrm{mg}$, copper $16 \mathrm{mg}$.

Tissue sampling: At the end of feeding experiment, 4 birds from each group were weighed and killed by decapitation under light anesthesia with diethyl ether. The whole small intestine were quickly excised and placed in the mixture of 3\% glutaraldehyde and $4 \%$ paraformaldehyde fixative solution in $0.1 \mathrm{M}$ cacodylate buffer ( $\mathrm{pH}$ 7.4). The intestinal segment from the gizzard to the pancreatic and bile ducts was regarded as duodenum, jejunum from the ducts to Meckel's diverticulum and ileum from the diverticulum to ileocecal-colonic junction. Each section was injected with the same fixative solution into the intestinal lumen and the middle section of which was taken.

Light microscopic examination: The segments were transverse cut approximately $2 \mathrm{~cm}$ from the duodenum, jejunum and ileum, fixed in Bouin's fixative solution at room temperature, embedded in paraplast and cut into $4 \mu \mathrm{m}$ thick cross section. Every tenth section was collected and stained with hematoxylin-eosin. The 4 light microscopic parameters were measured for each intestinal segment using an image analyzer (Nikon Cosmozone 1S, Nikon Co., Tokyo, Japan).

For villus heights measurement, the villi having the lamina propria were chosen with the length from the villus tip to the base, except the villus crypt was measured. A total of 16 villi were expressed as the mean villus heights in each bird. The villus areas were calculated from the basal width, apical width and villus heights with 16 calculations of the villus area for each 
bird. To measure one cell area, the epithelial cell layer was randomly measured at the middle of the villi and the number of cell nuclei within this layer was counted. The area of the epithelial layer was divided by this number, a total of 16 cell areas were counted for each bird. To measure the cells mitosis number in the villus crypt, four sections in each bird were randomly selected and counted mitotic cells having homogenous, basophilic nuclei intensely stained with hematoxylineosin. A total of cell mitosis numbers was counted from 4 different sections for each bird. Finally, the mean of each parameter of each bird was expressed as the mean for one group.

Scanning electron microscopic examination: Sections (approximately $2 \mathrm{~cm}$ in length) of duodenal, jejunal and ileal, which close to the light microscopic sample, were slit longitudinally. The intestinal contents were washed with $0.1 \mathrm{M}$ phosphate buffered saline $(\mathrm{pH}$ 7.4). The tissue sample were pinned flat and fixed in this flattened position in the mixture of $3 \%$ glutaraldehyde and $4 \%$ paraformaldehyde fixative solution in $0.1 \mathrm{M}$ cacodylate buffer ( $\mathrm{pH} \mathrm{7.4)}$ for $1 \mathrm{~h}$ at room temperature, cut into $4 \mathrm{~mm} \times 4 \mathrm{~mm}$ squares and continued fixed for $1 \mathrm{~h}$. The pieces were rinsed with $0.1 \mathrm{M}$ sodium cacodylate buffer and were post-fixed with $1 \%$ osmium tetroxide in a $0.1 \mathrm{M}$ ice-cold sodium cacodylate buffer for $2 \mathrm{~h}$. The specimens were dried in a critical point drying apparatus. The dried specimens were coated with platinum and observed at $8 \mathrm{kV}$ with Scanning Electron Microscope (SEM, Hitachi S-4300SE/N, Hitachi Ltd., Tokyo, Japan).

Statistical analyses: All data collected were analyzed by one-way Analysis Of Variance (ANOVA), supported by the Statistical Analysis System (SAS Institute, 2000). Statistical significant difference at $\mathrm{p}<0.05$ level due to treatments was separated by Duncan's multiple range tests.

\section{RESULTS}

Growth performance: Feed intake, body weight gain and the efficiency of feed utilization were not significantly different among groups (Table 2). However, feed intake was lower but body weight gain was better in all the experimental groups than that in the control. Among the experimental groups, the SCE + SPB group had the lowest feed intake, whereas the body weight gain was highest, resulting in higher feed efficiency.

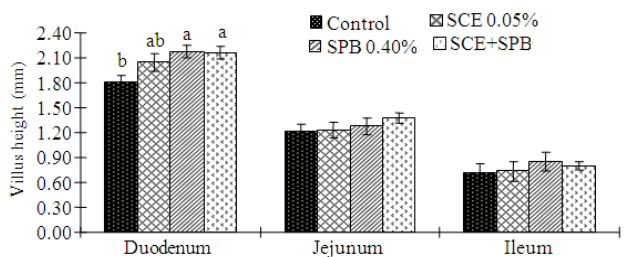

(a)
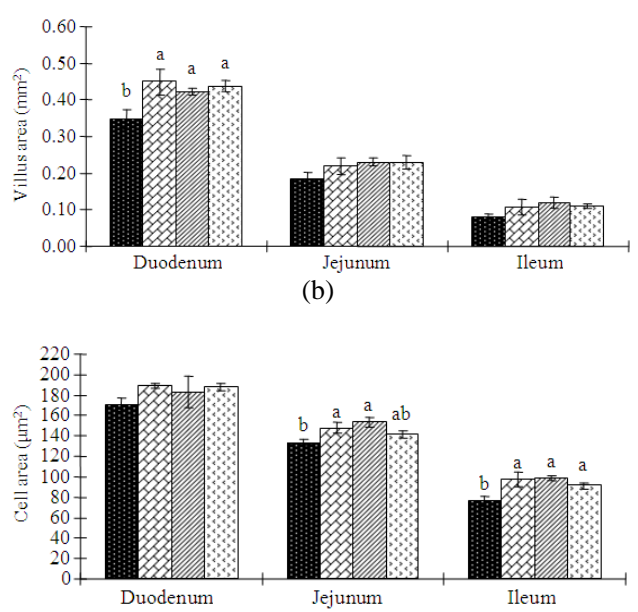

(c)

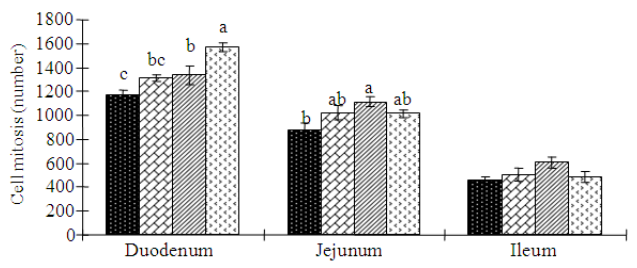

(d)

Fig. 1: Villus height, villus area, cell area and cell mitosis of duodenal, jejunal and ileal parts in the chickens fed dietary control, Sugar Cane Extract (SCE), Super-Biolicks (SPB) and the mixture of their $(\mathrm{SCE}+\mathrm{SPB})(\mathrm{n}=4)$. ${ }^{\mathrm{a}, \mathrm{b}, \mathrm{c}}$ : Means with different superscripts differ at $\mathrm{p}<0.05$

Histological analysis of light microscopic parameters: Compared with the control, most values of the intestinal villus height, villus area, cell area and cell mitosis number in each intestinal segment of the experimental groups were higher (Fig. 1). Values of duodenal villus height in SPB and SCE + SPB groups, duodenal villus area in all experimental groups, jejunal cell area in SCE and SPB groups and ileal cell area in all experimental groups were higher $(\mathrm{p}<0.05)$. Mitosis in the duodenum of the SPB and SCE + SPB groups was improved and was increased $(p<0.05)$ in the jejunum of the SPB group. 
Table 2: Growth performance in broiler fed dietary Sugar Cane Extract (SCE) and commercial probiotic (SPB) from 8-49 day old ( $\mathrm{n}=4$ )

\begin{tabular}{lrrrrr}
\hline & Control & SCE & SPB & \multicolumn{1}{c}{ SCE+SPB } & p-value \\
\hline Feed intake $(\mathrm{g})$ & $4855.4 \pm 75.90$ & $4731.3 \pm 89.90$ & $5142.2 \pm 297.50$ & $4608.6 \pm 219.800$ & 0.294 \\
Body weight gain $(\mathrm{g})$ & $2733.0 \pm 112.9$ & $2838.5 \pm 55.40$ & $2790.8 \pm 54.700$ & $2923.3 \pm 124.900$ & 0.541 \\
Feed efficiency & $0.562 \pm 0.017$ & $0.600 \pm 0.007$ & $0.547 \pm 0.027$ & $0.638 \pm 0.039$ & 0.103 \\
\hline
\end{tabular}

There are no significant differences between each group $(\mathrm{p}>0.05)$
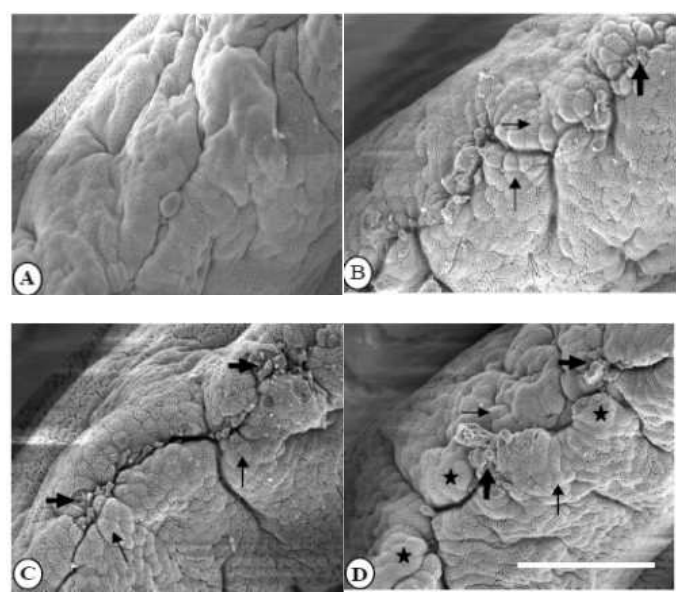

Fig. 2: Epithelial cells on the duodenal villus apical surface in the chickens fed dietary commercial (control; A), Sugar Cane Extract (SCE; B), Super-Biolicks (SPB; C) and the mixture of their $(\mathrm{SCE}+\mathrm{SPB} ; \mathrm{D})$ (arrows = protuberant cells; large arrows = some cell devoid of any microvilli; stars $=$ cell clusters). Scale bar, $50 \mu \mathrm{m}$

Morphology on the villus tip surface: Compared with comparatively flat epithelial cells of the control (Fig. 2A), the experimental groups had more protuberant cells (arrows) on the apical surface (Fig. 2B-D) and some cells around the central sulcus were devoid of any microvilli (large arrows). Cell clusters (stars), which were composed of many epithelial cells, were observed in the SCE + SPB group, resulting in a rough surface.

The jejunal villus tip surface of the control group was composed of flat cells, showing a smooth surface (Fig. 3A). However, in the experimental groups, most of the cells were slightly protuberant (Fig. 3B-D; arrows). In the SCE group, conspicuous cell clusters (stars) were observed.

The ileal villus apical surface in the control group had comparatively flat epithelial cells (Fig. 4A). In the SCE group (Fig. 4B), although each epithelial cell showed a similar morphology to the control, they formed cell clusters (stars) in some areas. In the SPB (Fig. 4C) and SCE + SPB (Fig. 4D) groups, conspicuous protuberances (arrow) of each epithelial cell and cell clusters (stars) appeared, with more greatly developed clusters in the latter.
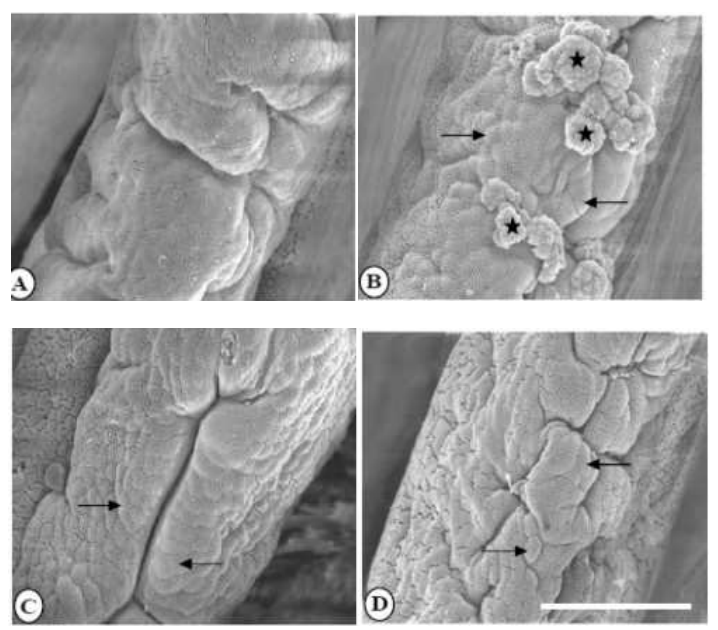

Fig. 3: Epithelial cells on the jejunal villus apical surface in the chickens fed dietary commercial (control; A), Sugar Cane Extract (SCE; B), Super-Biolicks (SPB; C) and the mixture of their $(\mathrm{SCE}+\mathrm{SPB} ; \mathrm{D})$ (arrows = faintly protuberated cell; stars $=$ cell clusters). Scale bar, $50 \mu \mathrm{m}$
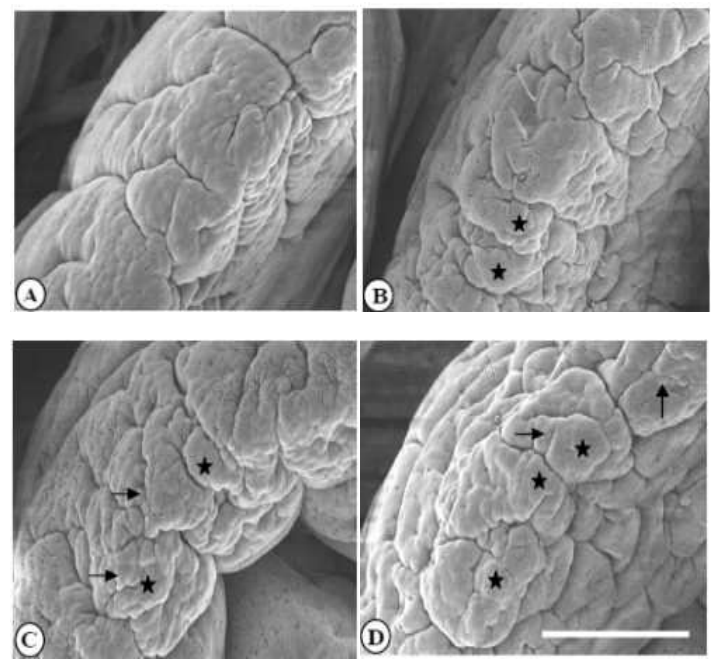

Fig. 4: Epithelial cells on the ileal villus apical surface in the chickens fed dietary commercial (control; A), Sugar Cane Extract (SCE; B), SuperBiolicks (SPB; C) and the mixture of their (SCE $+\mathrm{SPB}$; D) (arrow = conspicuous protuberances; stars $=$ cell clusters). Scale bar, $50 \mu \mathrm{m}$ 


\section{DISCUSSION}

In addition to nutritional-physiological studies on increasing poultry production with high quality of feeds, the exploitation of supplements to basal diets for maintaining the condition of the gut environment is also important. Recently, functional feeds such as probiotics and prebiotics have been used to enhance intestinal health and to obtain safe, reliable and high quality animal products without any medication and antibiotics. Probiotics are a live microbial feed additive that beneficially affects the host animal by improving its intestinal bacterial balance (Fuller, 1989). Chickens fed dietary probiotics showed improved body weight gain (Torres-Rodriguez et al., 2005), reduced mortality (Vicente et al., 2007) and enhanced feed conversion, ultimately resulting in an increase of broiler production (Willis et al., 2007). Also, in this study, the SPB group showed a $2 \%$ higher body weight gain than the control. Alternatively, SCE has displayed a wide range of biological effects including immunostimulation (El-Abasy et al., 2002), antiinflammatory activity (Ledon et al., 2003), activity as a vaccine adjuvant (El-Abasy et al., 2003) and anti-stress effects (Brekhman et al., 1978). Studies on chickens indicate that SCE acts as an adjuvant and has a protective effect against Eimeria tenella infection (El-Abasy et al., 2003). Other effects of SCE including antibacterial activities and superoxide anion scavenging activity (Takara et al., 2002) have been reported.

The combination of probiotics and other dietary substances has been the subject of renewed interest in health promotion due to their ability to enhance intestinal health. In piglets fed prebiotics, probiotics or synbiotics (a combination of the two) the population of bifidobacteria in the ileum increased and prebiotics and synbiotics increased their body weight gain (Shim et al., 2005). The dietary combination of probiotics and Biomannan oligosaccharides improved the feed conversion ratio in broiler vaccinated against coccidiosis (Sun et al., 2005). Also, in results described by Rowghani et al. (2007), a combination of probiotic and commercial feed additives had the most positive effect on performance in broilers. These results contrast with the result that broilers fed on either probiotics or mushroom extract were more likely to gain weight than those fed a mixture of them (Willis et al., 2007). Such conflicting results might depend on the type of substances mixed with probiotics. The present SCE and SCE + SPB induced a 3.8 and $6.9 \%$ higher body weight gain than the control, respectively. As SCE had growthpromoting effects (El-Abasy et al., 2002), the effects of dietary SCE + SPB on body weight gain might be due to the synergistic effect of SCE and SPB. This demonstrates that SCE would also be a good supplement with probiotics.

In the chickens fed the experimental diets, all values of light microscopic parameters were higher than those of the control. There is a strong relationship between intestinal mucosal histology and body weight change induced by intestinal function (Awad et al., 2006). Increases in villus length (Adibmoradi et al., 2006), villus width (Johnson and Jee, 1986), villus surface (Awad et al., 2006) and cell mitosis (Yamauchi et al., 2006) provide a greater surface area for higher nutrient absorptive potential and thus improve nutrient digestibility (Onderci et al., 2006). Conversely, short and narrow villi are associated with a decrease in body weight (Batal and Persons, 2002) and a reduction in the specific activity of the brush-border enzymes such as lactase and sucrase (Pluske et al., 1996) and mucosal enzymes such as peptidase and aminopeptidase (Hedmann et al., 2006). From these reports, the present higher values of light microscopic parameters in the SCE and SPB groups suggest that the intestinal villi might be hypertrophied by feeding SCE and SPB.

In the experimental groups, many kinds of morphological changes such as protuberant cells and cell clusters were found on the villus tip. Epithelial cells produced by proliferation within the crypts migrate up to the villus tip and are shed into the lumen. Therefore, many kinds of morphological steps such as cell apoptosis and cell protuberances are observed on the villus tip. These cell morphologies are altered by feeding (Hooper, 1956) and could be evaluated by scanning electron microscopy (Yamauchi et al., 2006). In rat intestinal villi, cell proliferation was depressed (Tessitore, 2000) and the number of apoptotic cells was increased (Boza et al., 1999; Tessitore, 2000) by starvation. Such cell proliferation was increased (Tessitore, 2000) and apoptotic cells were decreased after refeeding (Boza et al., 1999). These results suggest that protuberant cells indicate hypertrophy. As SCE induced growth-promoting (El-Abasy et al., 2002) and immunostimulatory effects (El-Abasy et al., 2003) and the probiotics could inhibit adhesion of pathogens to the chicken intestinal wall (Jin et al., 1996) by binding to intestinal mucus (Bernet et al., 1994), the observed protuberant cells may indicate hypertrophy as a result of feeding SCE or SPB. This corresponds with the fact that the SCE + SPB group showed the most conspicuously rough surface on the duodenal villus apical surface and that duodenal cell mitosis numbers were the highest in the SCE + SPB group. 
However, the SPB group had many conspicuous protuberant cells, corresponding with the result that all values of the light microscopic parameters were the highest in the SPB group. This agrees with the observations that probiotic strains could exert beneficial effects in the lower small intestine (Mottet and Michetti, 2005) and that dietary whole yeast or yeast cell wall could improve ileal mucosal development by promoting a greater ileal villus height in broilers (Zhang et al., 2005). A consideration of the higher values of light microscopic parameters in the SPB group than other groups and of the findings of similar studies in the literature, leads to the general conclusion that the present higher values of villi and protuberant cells in the ileum might be hypertrophied by SPB.

\section{CONCLUSION}

The results show that dietary SCE and SPB could induce hypertrophied intestinal villi and epithelial cells, resulting in improved growth performance. The fact that a synergistic effect was observed with regard to growth performance and intestinal histology in the SCE + SPB group suggests that SCE is a good supplementary partner for probiotics.

\section{REFERENCES}

Adibmoradi, M., B. Navidshad, J. Seifdavati and M. Royan, 2006. Effect of dietary garlic meal on histological structure of small intestinal in broiler chickens. J. Poult. Sci., 43: 378-383. http://www.jstage.jst.go.jp/article/jpsa/43/4/378/_pdf

Awad, W.A., J. Bohm, E. Razzazi-Fazeli, K. Ghareeb and J. Zentek, 2006. Effect of addition of a probiotic microorganism to broiler diets contaminated with deoxynivalenol on performance and histological alterations of small intestinal villi of broiler chickens. Poult. Sci., 85: 974-979. PMID: 16776464

Batal, A.B. and C.M. Parsons, 2002. Effects of age on development of digestive organs and performance of chicks fed a corn-soybean meal versus a crystalline amino acid diet. Poult. Sci., 81: 1338-1341. PMID: 12269613

Bernet, M.F., D. Brassart, J.R. Neeser and A.L. Servin, 1994. Lactobacillus acidophilus LA 1 binds to human intestinal cell line and inhibits cell attachment and cell invasion by enterovirulent bacteria. Gut, 35: 483-489. PMID: 8174985

Boza, J.J., D. Moennoz, J. Vuichoud, A.R. Jarret and D. Gaudard-de-Weck et al., 1999. Food deprivation and refeeding influence growth, nutrient retention and functional recovery of rats. J. Nutr., 129: 1340-1346. PMID: 10395596
Brekhman, I.I., I.F. Nestetenko, E.I. Khasina and P.S. Zorikov, 1978. Effect of yellow cane sugar on the performance and the degree of stress manifestations in animal. Vopr. Pitan., 6: 69-70. PMID: 726377

Dalloul, R.A., H.S. Lillehoj, T.A. Shellem and J.A. Doerr, 2003. Intestinal immunomodulation by vitamin a deficiency and Lactobacillus-based probiotic in Eimeria acervulina-infected broiler chickens. Avian Dis., 47: 1313-1320. PMID: 14708977

El-Abasy, M., M. Motobu, K. Shimura, K.J. Na and C.B. Kang et al., 2002. Immunostimulating and growth-promoting effects of Sugar Cane Extract (SCE) in chickens. J. Vet. Med. Sci., 64: 1061-1063. PMID: 12499696

El-Abasy, M., M. Motobu, K. Na, K. Shimura and K. Nakamura et al., 2003. Protective effects of Sugar Cane Extracts (SCE) on Eimeria tenella infection in chickens. J. Vet. Med., Sci., 65: 865-871. PMID: 12951418

Fuller, R., 1989. A Review. Probiotics in man and animals. J. Applied Bacteriol., 66: 365-378. PMID: 2666378

Gao, J., H.J. Zhang, S.H. Yu, S.G. Wu and I. Yoon et al., 2008. Effects of yeast culture in broiler diets on performance and immunomodulatory functions. Poult. Sci., 87: 1377-1384. PMID: 18577619

Guarner, F. and G.J. Schaafsma, 1998. Probiotics. Int. J. Food Microbiol., 39: 237-238. PMID: 9553803

Hedmann, M.S., M. Eskildsen, H.N. Laerke, C. Pedersen and J.E. Lindberg et al., 2006. Intestinal morphology and enzymatic activity in newly weaned pigs fed contrasting fiber concentrations and fiber properties. J. Anim. Sci., 84: 1375-1386. PMID: 16699094

Higgins, S.E., G.F. Erf, J.P. Higgins, S.N. Henderson and A.D. Wolfenden et al., 2007. Effect of probiotic treatment in broiler chicks on intestinal macrophage numbers and phagocytosis of Salmonella Enteritidis by abdominal exudate cells. Poult. Sci., 86: 2315-2321. PMID: 17954580

Hooper, C.E.S., 1956. Cell turnover in epithelial populations. J. Histochem. Cytochem., 4: 531-540. PMID: 13385475

Jin, L.Z., Y.W. Ho, N. Abdullah, M.A. Ali and S. Jalaludin, 1996. Antagonistic effects of intestinal Lactobacillus isolates on pathogens of chickens. Lett. Applied Microbiol., 23: 67-71. PMID: 8987444

Johnson, I.T. and J.M. Jee, 1986. Gastrointestinal adaptation in response to soluble non-available polysaccharides in the rat. Br. J. Nutr., 55: 497-505. PMID: 3676172 
Klein, G., A. Pack, C. Bonaparte and G. Reuter, 1998. Taxonomy and physiology of probiotic lactic acid bacteria. Int. J. Food Microbiol., 41: 103-125. PMID: 9704860

Ledon, N., A. Casaco, V. Rodriguez, J. Cruz and R. Gonzalez et al., 2003. Anti-inflammatory and analgesic effects of a mixture of fatty acid isolated and purified from sugar cane wax oil. Planta Med., 69: 367-369. PMID: 12709906

Mottet, C. and P. Michetti, 2005. Probiotics: Wanted dead or alive. Dig. Liver Dis., 37: 3-6. PMID: 15702852

Onderci, M., N. Sahin, K. Sahin, G. Cikim and A. Aydin et al., 2006. Efficacy of supplementation of-amylase-producing bacterial culture on the performance, nutrient use and gut morphology of broiler chickens fed a corn-based diet. Poult. Sci., 85: 505-510. PMID: 16553283

Pluske, J.R., M.J. Thompson, C.S. Atwood, P.H. Bird and I.H. Williams et al., 1996. Maintenance of villus height and crypt depth and enhancement of disaccharide digestion and monosaccharide absorption, in piglets fed on cows' whole milk after weaning. Br. J. Nutr., 76: 409-422. PMID: 8881713

Rowghani, E., M. Arab and A. Akbarian, 2007. Effects of probiotic and other feed additives on performance and immune response of broiler chicks. Int. J. Poult. Sci., 6: 261-265. http://www.pjbs.org/ijps/fin852.pdf

SAS Institute, 2000. SAS SQL Procedure User's Guide, Version 8. 1st Edn., SAS, Cary, ISBN: 10: 158025599X, pp: 576.

Shim, S.B., I.H. Williams and M.W.A. Verstegen, 2005. Effects of dietary fructo-oligosaccharides on growth, villous height and disaccharidase activity of the small intestine, $\mathrm{pH}, \mathrm{VFA}$ and ammonia concentration in the large intestine of weaned pigs. Acta. Agric. Scand, Section A-Anim. Sci., 55: 91-97. DOI: 10.1080/09064700500307201

Spring, P., C. Wenk, K. A. Dawson and K. E. Newman, 2000. The effects of dietary mannanoligosaccharides on cecal parameters and the concentrations of enteric bacteria in the ceca of salmonella-challenged broiler chicks. Poult. Sci., 79: 205-211.

http://ps.fass.org/cgi/content/short/79/2/205
Sun, X., A. McElroy, K.E. Webb, A.E. Sefton and C. Novak, 2005. Broiler performance and intestinal alterations when fed drug-free diets. Poult. Sci., 84: 1294-1302. PMID: 16156214

Takara, K., D. Matsui, K. Wada, T. Ichiba and Y. Nakasone, 2002. New antioxidative phenolic glycosides isolated from Kokuto non-centrifuged cane sugar. Biosci. Biotechnol. Biochem., 66: 29-35. PMID: 11866116

Tessitore, L., 2000. Apoptosis and cell proliferation are involved in the initiation of liver carcinogenesis by a subnecrogenic dose of diethynitrosamine in refed rats. J. Nutr., 130: 104-110. PMID: 10613775

Torres-Rodriguez, A., C. Sartor, S.E. Higgins, A.D. Wolfenden and L.R. Bielke et al., 2005. Effect of Aspergillus meal prebiotic (fermacto) on performance of broiler chickens in the starter phase and fed low protein diets. J. Applied. Poult. Res., 14: 665-669. http://japr.fass.org/cgi/content/abstract/14/4/665

Vicente, J.L., L. Avina, A. Torres-Rodriguez, B. Hargis and G. Tellez, 2007. Effect of a Lactobacillus spp. based probiotic culture product on broiler chicks performance under commercial conditions. Int. J. Poult. Sci., 6: 154-156. http://docsdrive.com/pdfs/ansinet/ijps/2007/154156.pdf

Willis, W.L., O.S. Isikhuemhen and S.A. Ibrahim, 2007. Performance assessment of broiler chickens given mushroom extract alone or in combination with probiotics. Poult. Sci., 86: 1856-1860. PMID: 17704371

Yamauchi, K., T. Buwjoom, K. Koge and T. Ebashi, 2006. Histological alterations of the intestinal villi and epithelial cells in chickens fed dietary sugar cane extract. Br. Poult. Sci., 47: 544-553. PMID: 17050097

Zhang, A.W., B.D. Lee, S.K. Lee, K.W. Lee and G.H. An et al., 2005. Effects of yeast (Saccharomyces cerevisiae) cell components on growth performance, meat quality and ileal mucosa development of broiler chicks. Poult. Sci., 84: 1015-1021. PMID: 16050118 